\title{
Fiber design and realization of point-by-point written fiber Bragg gratings in polymer optical fibers
}

\author{
Stefani, Alessio ; Stecher, Matthias; Town, Graham E.; Bang, Ole
}

Published in:

Proceedings of SPIE - The International Society for Optical Engineering

Link to article, DOI:

$10.1117 / 12.922029$

Publication date:

2012

Document Version

Peer reviewed version

Link back to DTU Orbit

Citation (APA):

Stefani, A., Stecher, M., Town, G. E., \& Bang, O. (2012). Fiber design and realization of point-by-point written fiber Bragg gratings in polymer optical fibers. Proceedings of SPIE - The International Society for Optical Engineering, 8426, 842617. https://doi.org/10.1117/12.922029

\section{General rights}

Copyright and moral rights for the publications made accessible in the public portal are retained by the authors and/or other copyright owners and it is a condition of accessing publications that users recognise and abide by the legal requirements associated with these rights.

- Users may download and print one copy of any publication from the public portal for the purpose of private study or research.

- You may not further distribute the material or use it for any profit-making activity or commercial gain

- You may freely distribute the URL identifying the publication in the public portal 


\title{
Fiber design and realization of point-by-point written fiber Bragg gratings in polymer optical fibers
}

\author{
Alessio Stefani ${ }^{a}$, Matthias Stecher $^{b}$, Graham E. Town $^{c}$ and Ole Bang ${ }^{a}$ \\ ${ }^{a}$ DTU Fotonik, Department of Photonics Engineering, Technical University of Denmark, \\ Ørsteds Plads, 2800 Kgs. Lyngby, Denmark; \\ ${ }^{b}$ Philipps University Marburg, 35032 Marburg, Germany; \\ ${ }^{c}$ Department of Electronic Engineering, Macquarie University, North Ryde NSW 2109,
}

Australia

\begin{abstract}
An increasing interest in making sensors based on fiber Bragg gratings (FBGs) written in polymer optical fibers (POFs) has been seen recently. Mostly microstructured POFs (mPOFs) have been chosen for this purpose because they are easier to fabricate compared, for example, to step index fibers and because they allow to tune the guiding parameters by modifying the microstructure. Now a days the only technique used to write gratings in such fibers is the phase mask technique with UV light illumination. Despite the good results that have been obtained, a limited flexibility on the grating design and the very long times required for the writing of FBGs raise some questions about the possibility of exporting POF FBGs and the sensors based on them from the laboratory bench to the mass production market. The possibility of arbitrary design of fiber Bragg gratings and the very short time required to write the gratings make the point-by-point grating writing technique very interesting and would appear to be able to fill this technological gap. On the other end this technique is hardly applicable for microstructured fibers because of the writing beam being scattered by the air-holes. We report on the design and realization of a microstructured polymer optical fiber made of PMMA for direct writing of FBGs. The fiber was designed specifically to avoid obstruction of the writing beam by air-holes. The realized fiber has been used to point-by-point write a $5 \mathrm{~mm}$ long fourth order FBG with a Bragg wavelength of $1518 \mathrm{~nm}$. The grating was inspected under Differential Interferometric Contrast microscope and the reflection spectrum was measured. This is, to the best of our knowledge, the first FBGs written into a mPOF with the point-by-point technique and also the fastest ever written into a polymer optical fiber, with less than 2.5 seconds needed.
\end{abstract}

Keywords: Polymer fiber, Bragg grating, Direct writing

\section{INTRODUCTION}

Many important industrial applications have found their solution in fiber-optic sensors based on fiber Bragg gratings (FBGs). ${ }^{1,2}$ Up to now the fiber material used has been silica, because of its low loss and resistance to high temperatures. However, for particular purposes, as strain sensing, polymer optical fiber (POF) FBGs are better suited because of the low Young's modulus and high failure strain of polymer compared to silica. ${ }^{1,3}$

Various configurations have been used to write fiber Bragg gratings in both step index and microstructured polymer optical fiber: continuous wave (CW) UV illumination in a ring interferometer ${ }^{4}$ and UV phase-mask. ${ }^{5-12}$ The required writing time is usually of 30-100 minutes for step index fibers ${ }^{5,6}$ and $60-270$ minutes for mPOF. ${ }^{7-11}$ Shorter writing times have been shown with a specially photosensitized fiber. ${ }^{12}$ Moreover in the microstructured POFs (mPOFs) the resulting gratings are also relatively weak. The long inscription time is a result of the relatively weak photosensitivity of polymers. The air-hole microstructure obstructs the core mPOFs and therefore contributes to the writing time increase, compared to solid POFs, and to the relatively weak gratings. ${ }^{13-15}$ Long writing times is a serious problem for applications requiring mass production.

Further author information: (Send correspondence to Alessio Stefani)

Alessio Stefani: E-mail: (e-mail: alste@fotonik.dtu.dk)

Matthias Stecher at the time of this work he was supported by a Macquarie University postgraduate scholarship. 
Point-by-point grating writing, with high intensity ultrashort laser pulses, has been previously used to overcome the low photosensitivity of polymer waveguides. ${ }^{16-18}$ This approach has been demonstrated also in step index silica fibers, ${ }^{19,20}$ and in silica waveguides. ${ }^{21}$ Advantages of direct-writing are also: flexibility in the grating design, ${ }^{22}$ and avoiding the expense of the phase mask and of use of dopants or hydrogenation to increase the photosensitivity. However, the problem of obstruction by the microstructure still needs to be overcome.

It would be possible to fill the holes with a material with similar index to the host to overcome scattering by the microstructure. However this is not trivial since filling the holes can be difficult to achieve in practice and significantly reduces the strong confinement achievable in air-filled microstructures ${ }^{23}$ and it would be difficult to get the liquid out of the fiber.

The first grating point-by-point written in a simple silica microstructured fiber was recently demonstrated by Geernaert at $a l .{ }^{24}$ The fiber used is made by only two parallel layers of holes. Having only one layer of holes to go through during writing minimized scattering and diffraction of the writing beam. However there is still a tradeoff between confinement of the guided mode and access to the core by the grating writing beam.

In this paper we report on the design of a mPOF specifically for direct writing, and on the investigation of the writing parameters for polymers and on the grating realization.

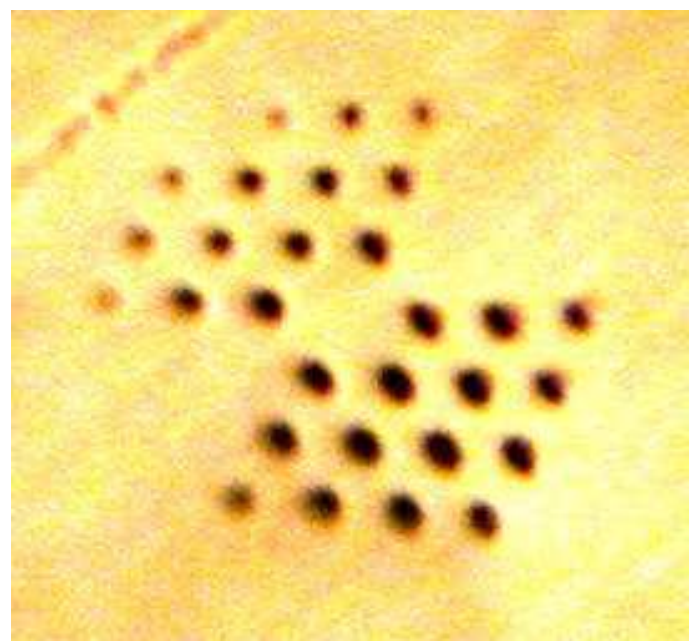

Figure 1. Cross section of the realized mPOF structure designed for direct writing.

\section{FIBER DESIGN}

The fiber design aimed to let the writing focused laser beam to pass between the air-holes in order to encounter minimal scattering before reaching the core. To serve the purpose 3 holes were removed creating an "opening" in the 3 ring hexagonal microstructure (see Fig. 1-2). As the fiber was symmetric, 6 holes in total were removed. In this way access for the focused $800 \mathrm{~nm}$ laser beam was created through the microstructure on both sides. The hole to hole distance was made so that the beam could also pass the first ring of holes without facing any interface. The spot size of the focused beam was estimated just above $1 \mu \mathrm{m}$ and, as we aim for a hole to pitch ratio of 0.42 (condition to make the $\mathrm{mPOF}$ endlessly single mode with all holes present in the cladding ${ }^{25}$ ), a minimum pitch of $2 \mu \mathrm{m}$ was required. The mode was simulated (with the commercial software COMSOL) and the confinement loss were calculated. Since the material has about $100 \mathrm{~dB} / \mathrm{m}$ loss at $1550 \mathrm{~nm},{ }^{3}$ the resulting loss of the order of less than $1 \mathrm{~dB} / \mathrm{m}$ were considered negligible.

\section{FIBER FABRICATION}

The microstructure of fabricated fiber is shown in Fig. 1. The fiber has a diameter of $130 \mu \mathrm{m}$ and a slightly asymmetric microstructure with hole diameters between 1 and $1.5 \mu \mathrm{m}$. The pitch is $3.5 \mu \mathrm{m}$, resulting in a hole to pitch ratio between 0.29 and 0.43 . 


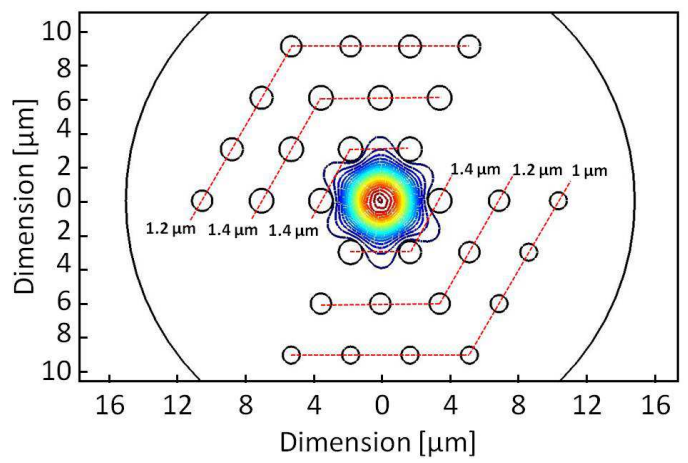

Figure 2. COMSOL simulation of the guided mode in the fiber. The simulated structure has a pitch of $3.5 \mu \mathrm{m}$ and hole diameters varying from 1 to $1.4 \mu \mathrm{m}$ in order to match as much as possible the real structure.

A simulation of the realized fiber was also made in order to estimate the guiding properties. In the simulation a pitch of $3.5 \mu \mathrm{m}$ and hole diameters varying from 1 to $1.4 \mu \mathrm{m}$ were used (as shown in Fig. 2) in order to match as much as possible the real structure. The fundamental mode for a wavelength of $1.52 \mu \mathrm{m}$ is shown in Fig. 2 . The simulated fundamental mode has an effective refractive index of $n_{\text {eff }}=1.48037$ (using 1.49 as material refractive index) and from the imaginary part a confinement loss of $0.67 \mathrm{~dB} / \mathrm{m}$ is calculated.

\section{GRATING WRITING}

Before writing the grating, slab samples of PMMA were investigated in order to determine necessary pulse energy to use during writing.

\subsection{DAMAGE INVESTIGATION}

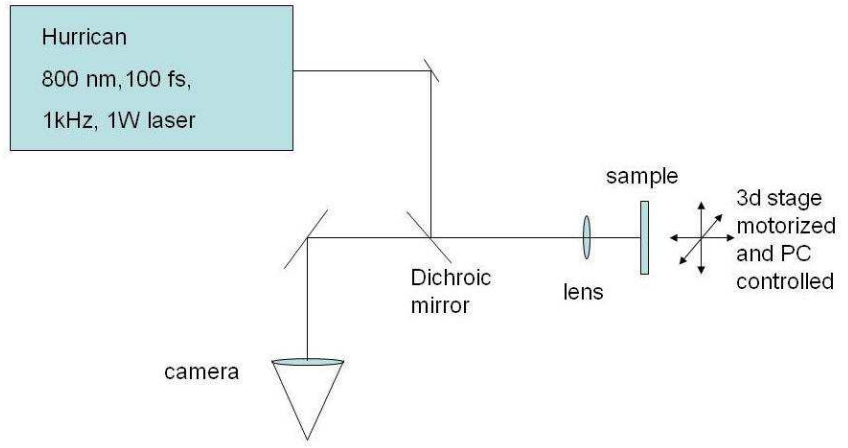

Figure 3. Schematic of the set-up used for point by point writing.

The grating writing set-up ${ }^{26}$ is shown in Fig. 3. A regeneratively amplified, low-repetition rate, Ti:sapphire femtosecond laser system (Hurricane, Spectra-Physics) was used to produce the refractive index change. The output of the laser has $100 \mathrm{fs}$ pulses with a central wavelength of $800 \mathrm{~nm}$. A series of neutral density filters at the output of the laser was used to reduce and control the pulse energy. The beam was then reflected by a dichroic mirror, which allowed to observe the writing process with a CCD camera. After the dichroic mirror the light beam was focused with a 40x objective lens into the sample. The sample was mounted on an automated and computer controlled 3 axes translation stage (Aerotech FA-130, Aerotech ABL200) that can move with $200 \mathrm{~nm}$ resolution.

The test have been run by inscribing a series of lines of damages spots, and for each line one parameter was changed. two different parameters have been investigated: the pulse energy and the writing speed. Moreover 
various thermal treatments were applied to investigate the effect of residual strain. A series of $6 \times 4$ lines have been written every time. In particular, the test set used 6 different energies $(100,90,80,70,60,50 \mathrm{~nJ})$ and 4 different spacing between the spots $(5,3,2,1 \mu \mathrm{m})$. The laser repetition rate used is $500 \mathrm{~Hz}$ and the different spacing was realized by using the following speeds for the stage: 150, 90, 60, $30 \mathrm{~mm} / \mathrm{min}$. Single shot damages spots, $170 \mu \mathrm{m}$ below the sheet surface, were used.

Fig. 4 the resulting DIC image of the test. It is possible to see that the $1 \mu \mathrm{m}$ spaced spots can almost not be distinguished, creating a full line. This factor poses a limitation on the grating period.
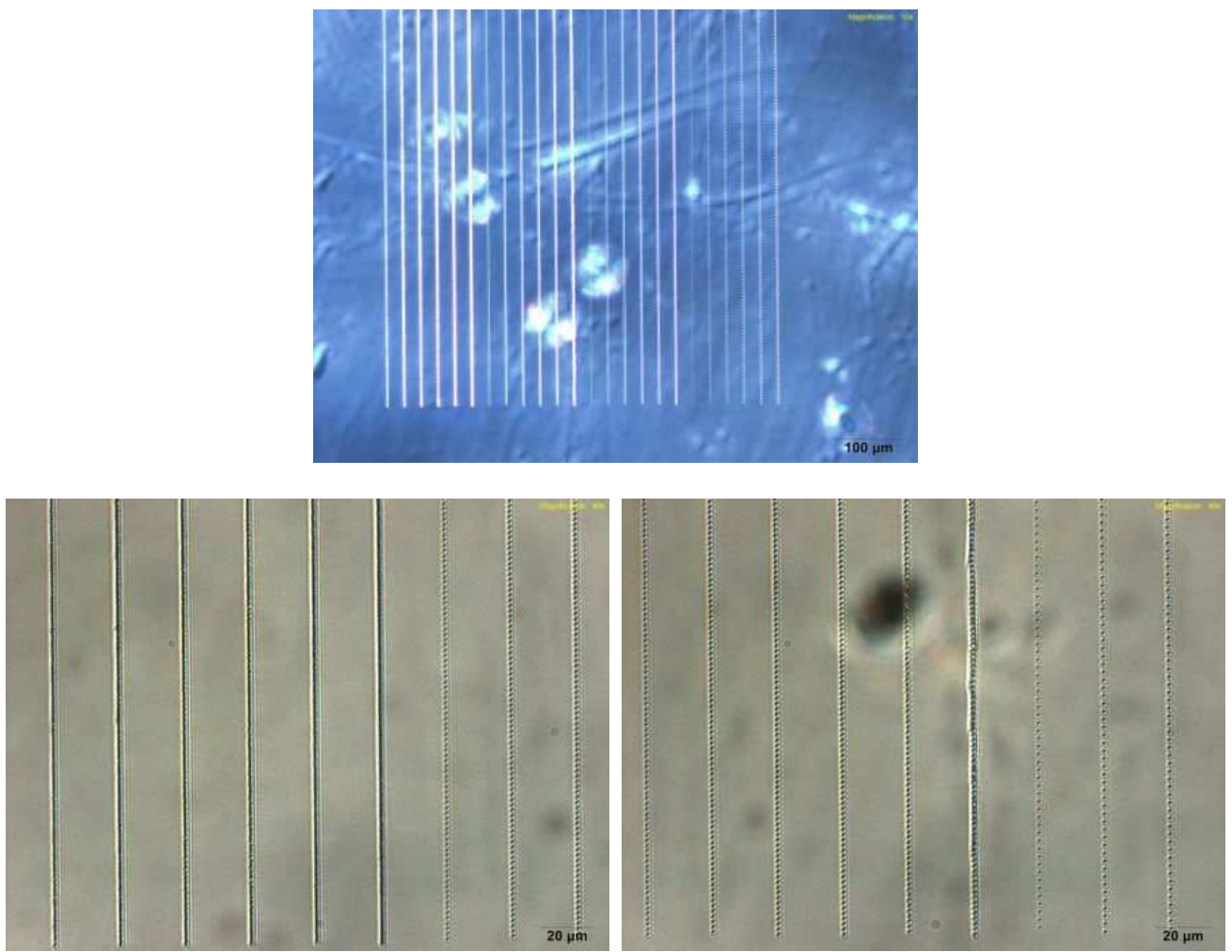

Figure 4. DIC microscope image of the spots. The image top image is an overview of the $6 \times 4$ lines. The images in the bottom are zoom in of the $1 \mu \mathrm{m}$ (left) and $2 \mu \mathrm{m}$ (right) spaced spots.

The slabs were then placed in the oven (100C) overnight. The spots were then remeasured and a second set was then written. The slabs were again placed in the oven for 5 days and both set were remeasured. In Fig. 5 the result of the two annealing process is showed for the $1 \mu \mathrm{m}$ spaced spots. Some stress line can be seen. The spots with larger spacing did not show significant difference.

After one day in the oven the writing was repeated. Fig 6 shows the resulting spots and the same spots after 5 days annealing.

In this situation is possible to see how the low energy spots do not overlap, showing a smaller diffusion of the damage area. No significant difference can be seen after annealing.

\subsection{FBG}

After choosing $75 \mathrm{~nJ}$ as energy. Grating writing in the optical fiber was performed. The alignment of the fiber was done visually with a CCD camera

A 4th order grating at $\lambda_{B}=1520 \mathrm{~nm}$ was targeted. This grating order was the minimum for which two consecutive spots (with diameter around $1 \mu \mathrm{m}$ ) would not overlap (since the fiber was not preanneled). We find 

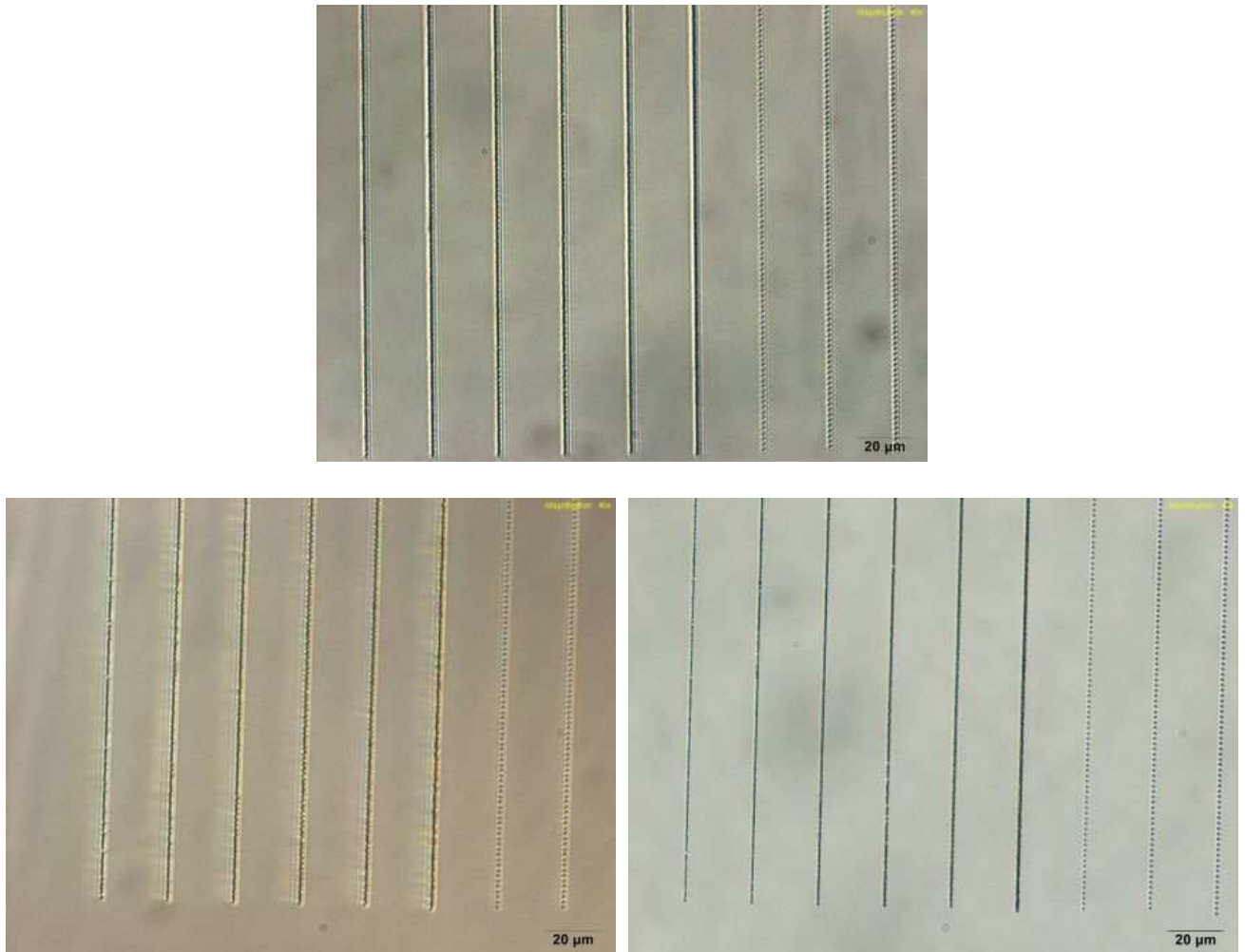

Figure 5. DIC microscope image of the spots. $1 \mu \mathrm{m}$ spaced spots (top). Bottom: one night at 100 deg (left) and 5 more days at $100 \mathrm{deg}$ (right).
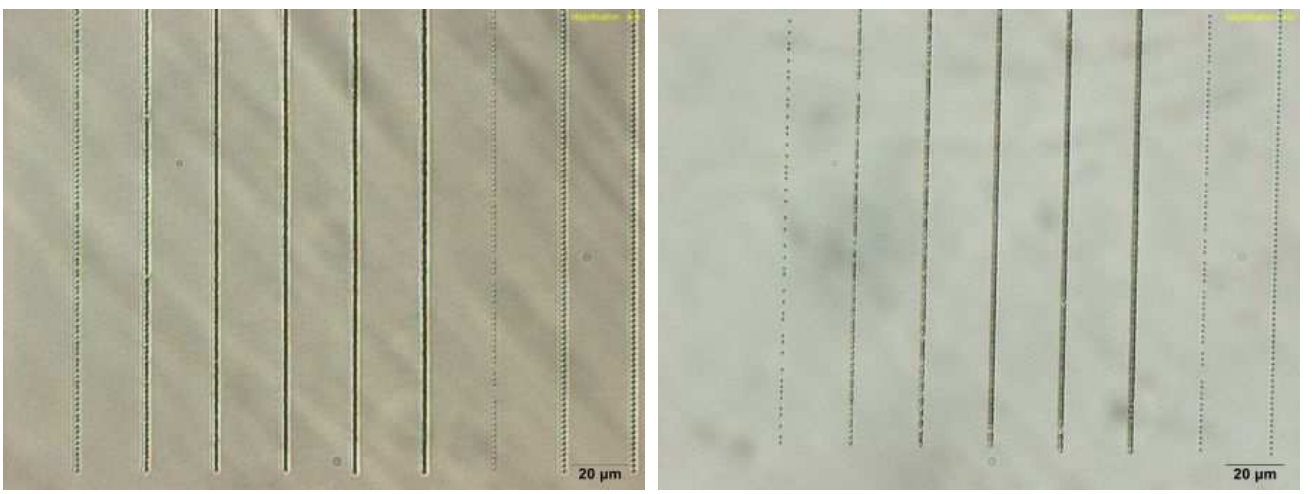

Figure 6. DIC microscope image of the spots. $1 \mu \mathrm{m}$ spaced spots written after annealing (left) and the same spots after 5 days annealing (right).

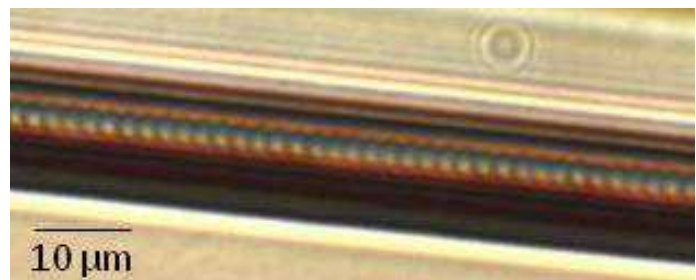

Figure 7. DIC microscope image of the FBG. The image was taken with a 40x magnification lens. A modulation with about $2 \mu \mathrm{m}$ period can be seen at the center of the fiber and in particular at the center of the microstructure.

a grating period of $\Lambda=\frac{4 \lambda_{B}}{2 n_{e f f}}=2.053 \mu \mathrm{m}$, using the calculated $n_{e f f}=1.48037$. We then calculate a necessary 
translation speed of $2.053 \mu \mathrm{m} \times 1 \mathrm{kHz}=2.053 \mathrm{~mm} / \mathrm{s}$, calculated for the case of single pulse per spot.

The fiber was examined afterwards under a differential interference contrast (DIC) microscope (Olympus). The resulting image is shown in Fig. 7. From the image a clear modulation of the refractive index is visible. The modulation period is around $2 \mu \mathrm{m}$, which is in agreement with the design spacing.

A reflection spectrum was also measured and will be presented.

\section{CONCLUSIONS}

In conclusion we have shown a new fiber design, and it's realization, for direct writing of FBGs in microstructured fibers. We showed investigation of the spots on a polymer slab for different spacing, energies, and annealing conditions. We also show the grating writing in the designed fiber. The grating is a fourth order grating resulting with Bragg wavelength at $1518.67 \mathrm{~nm}$.

The proof that the direct writing technique can work for mPOFs could solve one of the crucial problems of mPOF FBG fabrication, i.e. the long writing time, which is generally above 60 minutes for mPOFs. ${ }^{1}$

We note that direct writing could allow grating writing in fibers made with non-photosensitive materials, such as low loss perfluorinated POFs. ${ }^{3}$

\section{ACKNOWLEDGMENTS}

We would like to acknowledge support from the Danish National Advanced Technology Foundation and the Australian National Fabrication Facility.

\section{REFERENCES}

[1] D. Webb and K. Kalli, "Polymer fiber Bragg gratings", in Fiber Bragg Grating Sensors: Recent Advancements, Industrial Applications and Market Exploitation, 2009, pp. 1-20, A. Cusano, A. Cutolo, and J. Albert, eds. (2009 Bentham Science Publishers Ltd).

[2] A.D. Kersey, M.A. Davis, H.J. Patrick, M. LeBlanc, K.P. Koo, C.G. Askins, M.A. Putnam, and E.J. Friebele, "Fiber grating sensors", J. Lightwave Technol., vol. 15, 1442, 1997.

[3] M. Large, L. Poladian, G. Barton, and M.A. van Eijkelenborg, Microstructured Polymer Optical Fibres, (Springer, 2008), pp. 1-20.

[4] Z. Xiong, G.D. Peng, B. Wu, and P.L. Chu, "Highly tunable Bragg Gratings in single-mode polymer optical fibers", IEEE Photon. Technol. Lett., vol. 11, pp. 352-354, 1999.

[5] W. Yuan, A. Stefani, M. Bache, T. Jacobsen, B. Rose, N. Herholdt-Rasmussen, F.K. Nielsen, S. Andresen, O.B. Sørensen, K.S. Hansen, and O. Bang, "Improved thermal and strain performance of annealed polymer optical fiber Bragg gratings", Opt. Commun., Vol. 28, pp. 176-182, 2011.

[6] H.Y. Liu, G.D. Peng, and P.L. Chu, "Polymer fiber Bragg gratings with 28-dB transmission rejection", IEEE Photon. Technol. Lett. 14, 935-937, 2002.

[7] H. Dobb, D.J. Webb, K. Kalli, A. Argyros, M.C.J. Large, and M.A. van Eijkelenborg, "Continuous wave ultraviolet light-induced fiber Bragg gratings in few- and single- moded microstructured polymer optical fibers", Opt. Lett., vol. 30, 3296, 2005.

[8] I.P. Johnson, W. Yuan, A. Stefani, K. Nielsen, H.K. Rasmussen, L. Khan, D.J. Webb, K. Kalli, O. Bang, "Optical fibre Bragg grating recorded in TOPAS cyclic olefin copolymer", Electron. Lett., vol. 47, 271-272, 2011.

[9] W. Yuan, L. Khan, D.J. Webb, K. Kalli, H.K. Rasmussen, A. Stefani, O. Bang, "Humidity insenssitive TOPAS polymer fiber Bragg grating sensor", Opt. Express, vol. 19, 19731-19739, 2011.

[10] A. Stefani, W. Yuan, C. Markos, O. Bang, "Narrow bandwidth $850 \mathrm{~nm}$ fiber Bragg gratings in few-mode polymer optical fibers", IEEE Photon. Technol. Lett., vol. 23, 660-662, 2011.

[11] W. Yuan, A. Stefani, O. Bang, "Tunable polymer fiber Bragg grating (FBG) inscription: fabrication of dual-FBG temperature compensated polymer optical fiber strain sensors", IEEE Photon. Technol. Lett, vol. 24, 401-403, 2012. 
[12] C. Zhang, K. Carroll, D.J. Webb, I. Bennion, K. Kalli, G. Emiliyanov, O. Bang, E. Kjær, and G.D. Peng, "Recent progress in polymer optical fibre gratings", Proc. of SPIE, 70044G, 2008.

[13] G.D. Marshall. D.J. Kan, A.A. Asatryan, L.C. Botten, M.J. Withford, "Transverse coupling to the core of a photonic crystal fiber: the photo-inscription of gratings, Opt. Express, vol. 15, 7876-7887, 2007.

[14] T. Baghdasaryan, T. Geernaert, F. Berghmans, and H. Thienpont, "Geometrical study of a hexagonal lattice photonic crystal fiber for efficient femtosecond laser grating inscription", Opt. Express, 7705-7716, 2011.

[15] T. Baghdasaryan, T. Geernaert, M. Becker, K. Schuster, H. Bartelt, M. Makara, P. Mergo, F. Berghmans, H. Thienpont, "Influence of Fiber Orientation on Femtosecond Bragg Grating Inscription in Pure Silica Microstructured Optical Fibers", IEEE Photon. Technol. Lett., vol. 23, 1832-1834, 2011.

[16] P.J. Scully, D. Jones, D.A. Jaroszynski, "Femtosecond laser irradiation of polymethylmethacrylate for refractive index gratings", J. Opt. A: Pure Appl. Opt., vol. 5, S92-S96, 2003.

[17] C. Wochnowski, Y. Cheng, K. Meteva, K. Sugioka, K. Midorikawa, S. Metev, "Femtosecond-laser induced formation of grating structures in planar polymer substrates", J. Opt. A: Pure Appl. Optics, vol. 7, 493-501, 2005.

[18] A.J. Lee, A. Rahmani, J.M. Dawes, G.D. Marshall, M.J. Withford, "Point-by-point inscription of narrowband gratings in polymer ridge waveguides", Appl. Physics A, 90, 273-276, 2008.

[19] A. Martinez, I.Y. Khrushchev, I. Bennion, "Direct inscription of Bragg gratings in coated fibers by an infrared femtosecond laser", Opt. Lett., vol. 31, 1603-1605, 2006.

[20] A. Martinez, M. Dubov, I. Khrushchev, I. Bennion, "Direct writing of fiber Bragg gratings by femtosecond laser", Electron. Lett., vol. 40, 2004.

[21] G.D. Marshall, M. Ams, M.J. Withford, "Direct laser written waveguide-Bragg gratings in bulk fused silica", Opt. Lett., vol. 31, 2690-2691, 2006.

[22] G.D. Marshall, R.J. Williams, N. Jovanovic, M.J. Steel, and M.J. Withford, "Point-by-point written fiberBragg gratings and their application in complex grating designs", Opt. Express, vol. 18, 19844-19859, 2010.

[23] H.R. Sørensen, J. Canning, J. Lægsgaard, K. Hansen, and P. Varming, "Liquid filling of photonic crystal fibres for grating writing", Opt. Commun., vol. 270, 207-210, 2007.

[24] T. Geernaert, K. Kalli, C. Koutsides, M. Komodromos, T. Nasilowski, W. Urbanczyk, J. Wojcik, F. Berghmans, H. Thienpont, "Point-by-point fiber Bragg grating inscription in free-standing step-index and photonic crystal fibers using near-IR femtosecond laser", Opt. Lett., vol. 35, 1647-1649, 2010.

[25] N.A. Mortensen, "Semianalytical approach to short-wavelength dispersion and modal properties of photonic crystal fibers", Opt. Lett., vol. 30, 1455-1457, 2005.

[26] M. Ams, G.D. Marshall, D.J. Spence, M.J. Withford, "Slit beam shaping method for femtosecond laser direct-write fabrication of symmetric waveguides in bulk glasses", Opt. Express, vol. 13, 5676-5681, 2005. 